\title{
SUPPLEMENTARY DESCRIPTION OF UNGUIZETES CLAVATUS AOKI, 1967 (ACARI, ORIBATIDA, MOCHLOZETIDAE) ON THE BASIS OF VIETNAMESE SPECIMENS
}

\author{
Sergey G. Ermilov
}

Tyumen State University, Tyumen, Russia

E-mail: ermilovacari@yandex.ru

\begin{abstract}
The oribatid mite, Unguizetes clavatus Aoki, 1967 (Oribatida, Mochlozetidae), is redescribed and illustrated in detail on the basis of specimens collected from Tam Dao National Park in Northern Vietnam. The main morphological traits for this species are summarized.
\end{abstract}

KEY WORDS: Oribatid mite, Unguizetes clavatus, systematics, morphology, supplementary description, Vietnam.

DOI: 10.21684/0132-8077-2017-25-2-97-107

\section{INTRODUCTION}

The oribatid mite Unguizetes clavatus (Acari, Oribatida, Mochlozetidae) was described by Aoki (1967) from Thailand. At present, it is distributed in the Oriental and the Eastern Palaearctic regions (Subías 2004, online version 2017).

During taxonomic survey of oribatids from Vietnam, I found $U$. clavatus. In the Vietnamese fauna this species was registered for the first time by Golosova (1983), after which it has been recorded repeatedly (e.g. Ermilov and Anichkin 2013a, $b, 2014$ ). The original description (Aoki 1967) is not complete (it lacks information about some morphological structures and their measures, leg setation and solenidia, morphology of gnathosoma; also, body surface poorly described). The main goal of the paper is to present a supplementary description of $U$. clavatus, on the basis of specimens from Northern Vietnam, and to summarize the main morphological traits, which will help with the identification of this species in the future.

This work is part of continuing study of oribatid mites of Vietnam (e.g. Ermilov 2015, 2016b, 2017; Minor and Ermilov 2015; Ermilov and Starý 2017a, b; Minor et al. 2017).

\section{MATERIAL AND METHODS}

Material examined. Six specimens: two females and four males: Northern Vietnam, Tam Dao National Park, 1,080 $\mathrm{m}$ a.s.l., primary foggy forest between Dinh Thien Thi Mt. and Dính Mang Chi Mt., litter and soil sample (No. VIE-166), 18.X.1988 (collected by J. Starý and T.T. Nguen).

Methods. Specimens were mounted in lactic acid on temporary cavity slides for measurement and illustration. The body length was measured in lateral view, from the tip of the rostrum to the posterior edge of the ventral plate. Notogastral width refers to the maximum width behind pteromorphs in dorsal aspect. Lengths of body setae were measured in lateral aspect. All body measurements are presented in micrometers. Formulas for leg setation are given in parentheses according to the sequence trochanter-femur-genu-tibia-tarsus (famulus included). Formulas for leg solenidia are provided in square brackets according to the sequence genu-tibia-tarsus. Morphological terminology used in this paper follows that of F. Grandjean: see Travé and Vachon (1975) for references, Norton (1977) for leg setal nomenclature, and Norton and Behan-Pelletier (2009) for overview. Drawings were made with a camera lucida using a Leica transmission light microscope "Leica DM 2500". Microscope images were taken with an AxioCam ICc5 digital camera.

\section{SYSTEMATICS}

\section{Unguizetes clavatus Aoki, 1967 \\ Adult}

Figs. 1-24

Supplementary description. Measurements. Body length: 813-879 (six specimens: two females and four males); notogaster width: 614-680 (six specimens). No differences between females and males in the body sizes.

Integument (Figs. 1-5, 11-15, 19). Body color brown to dark brown. Surface of notogaster, pteromorphs, anogenital region and anal plates heavily lineolate, with short (length up to 16) depressed, distinct lines (elongate foveolae), which are connected in lateral and posterior parts of notogaster and partially forming striate ornamentation or reticulate pattern. Foveolae instead lines present in lateral parts of pteromorphs and near genital aper- 


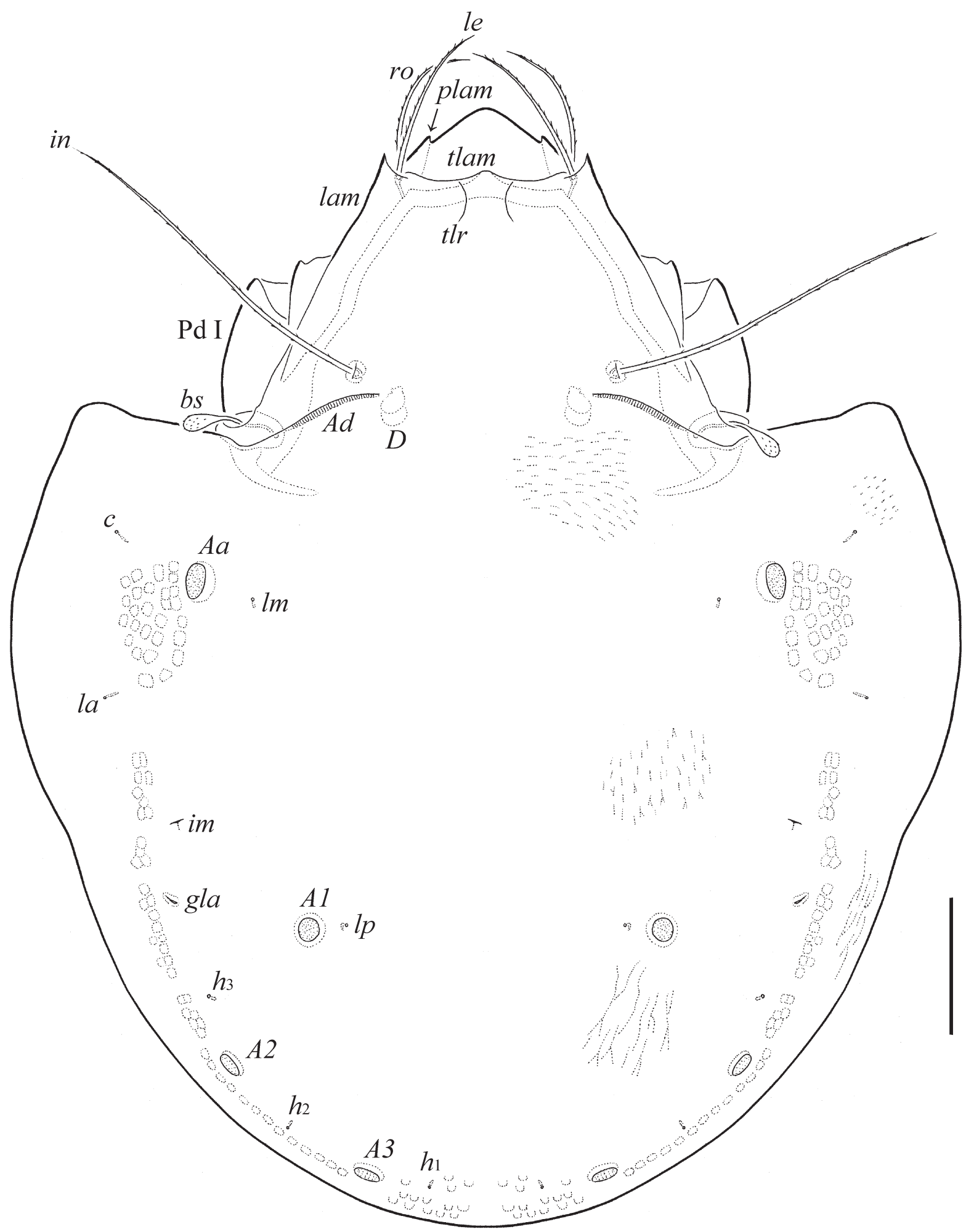

Fig. 1. Unguizetes clavatus Aoki, 1967: dorsal view. Scale bar $100 \mu \mathrm{m}$.

ture. Lateral sides of prodorsum (between bothridia and acetabula I, II) densely microgranulate (diameter of granules up to 1).

Prodorsum (Figs. 1-3, 6, 16-19). Rostrum broadly rounded (clearly visible in dorsofrontal view). Lamellae (lam) slightly longer than half of prodorsum, with well-developed cusps having one lateral tooth, medial teeth absent. Translamella (tlam) thick, slightly triangularly convex medially, with two thin, perpendicular posterior ridges $(\mathrm{tlr})$. Prolamellae present, creating illusion of two lateral teeth on the rostrum in dorsal view, with one lateroperpendicular ridge $(p l r)$ in median parts. Sublamellae (slam) longer than half of lamellae. 


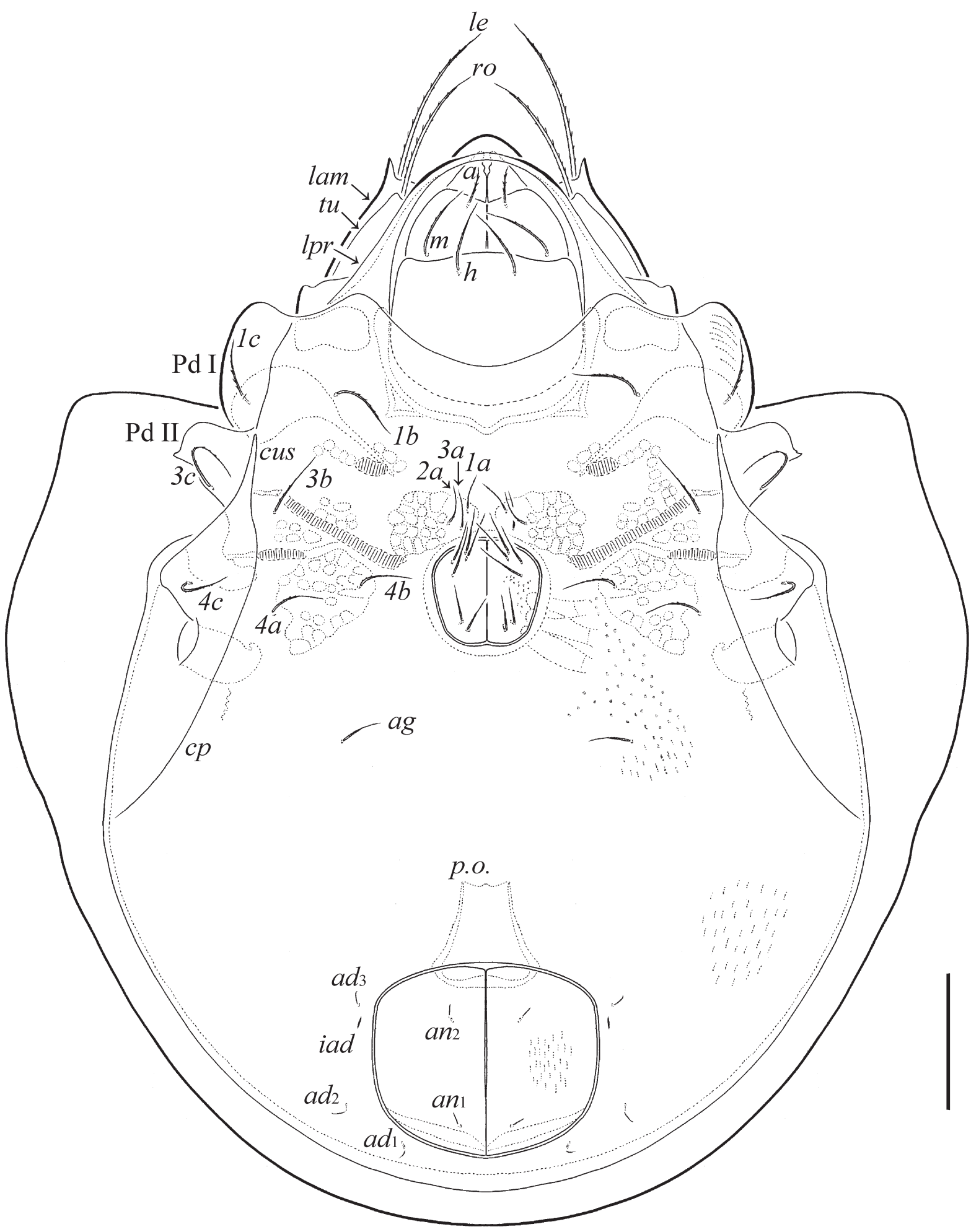

Fig. 2. Unguizetes clavatus Aoki, 1967: ventral view (legs not shown). Scale bar $100 \mu \mathrm{m}$.

Sublamellar porose areas $(A l)$ oval (20-26×14-16). Tutoria $(t u)$ without distal teeth. Lateral prodorsal ridges ( $p l r)$ present. Rostral (ro, 106-114), lamellar (le, 135-151) and interlamellar (in, 270-278) setae setiform, barbed. Exobothridial setae (ex, 49-61) thin, barbed. Bothridial setae ( $b s, 44-65)$ with shorter, smooth stalks (16-24) and longer (28-41), clavate, barbed heads. Ridges (br) near bothridia slightly developed. Dorsophragmata $(D)$ slightly elongated longitudinally. Dorsosejugal porose areas (Ad) band-like, transversely oriented.

Notogaster (Figs. 1, 3-5, 11-14). Pteromorphs well-developed, broadly rounded laterally. Four pairs of porose areas, Aa oval (28-36 $\times 16-20), A 1$, 

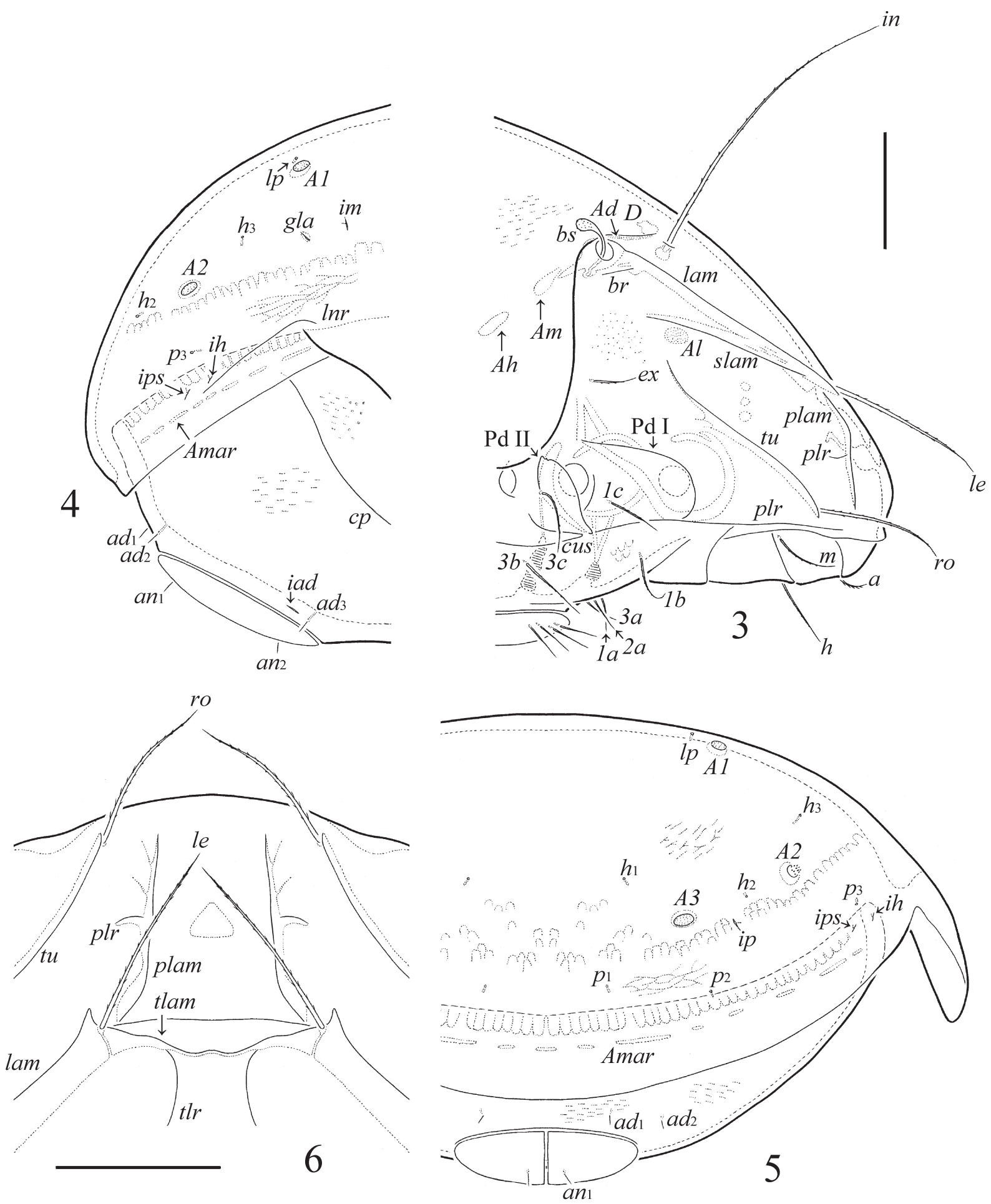

Figs. 3-6 Unguizetes clavatus Aoki, 1967: 3-anterior part of body, lateral view (legs not shown); 4 - posterior part of body, lateral view; 5-posterior view (part of left half not shown); 6-rostrum, dorsoanterior view. Scale bars $100 \mu \mathrm{m}$.

$A 2$ and $A 3$ rounded (20-28), with distinct borders. Setal alveoli $l m$ inserted medially or posteromedially to $A a$. Lyrifissures im, ip, ips and $i h$ and opisthonotal gland openings $(\mathrm{gla})$ clearly visible, $i a$ not found, ips and ih located close to each other, lateral to setal alveoli $p_{3}$. Lateral notogastral ridges (lnr) present.
Gnathosoma (Figs. 2, 3, 20-23). Typical for Unguizetes (Ermilov 2016a). Subcapitulum longer than wide $(213-217 \times 172-180)$. Three pairs of subcapitular setae setiform, $h(65-69)$ and $m$ (57-61) barbed, $a$ (32-41) ciliate. Two pairs of adoral setae $\left(o r_{1}, o r_{2}, 24\right)$ slightly thickened, heavily barbed. Palps with length 143-147. Postpalpal setae (6) spiniform, smooth. Chelicerae (155-159) 


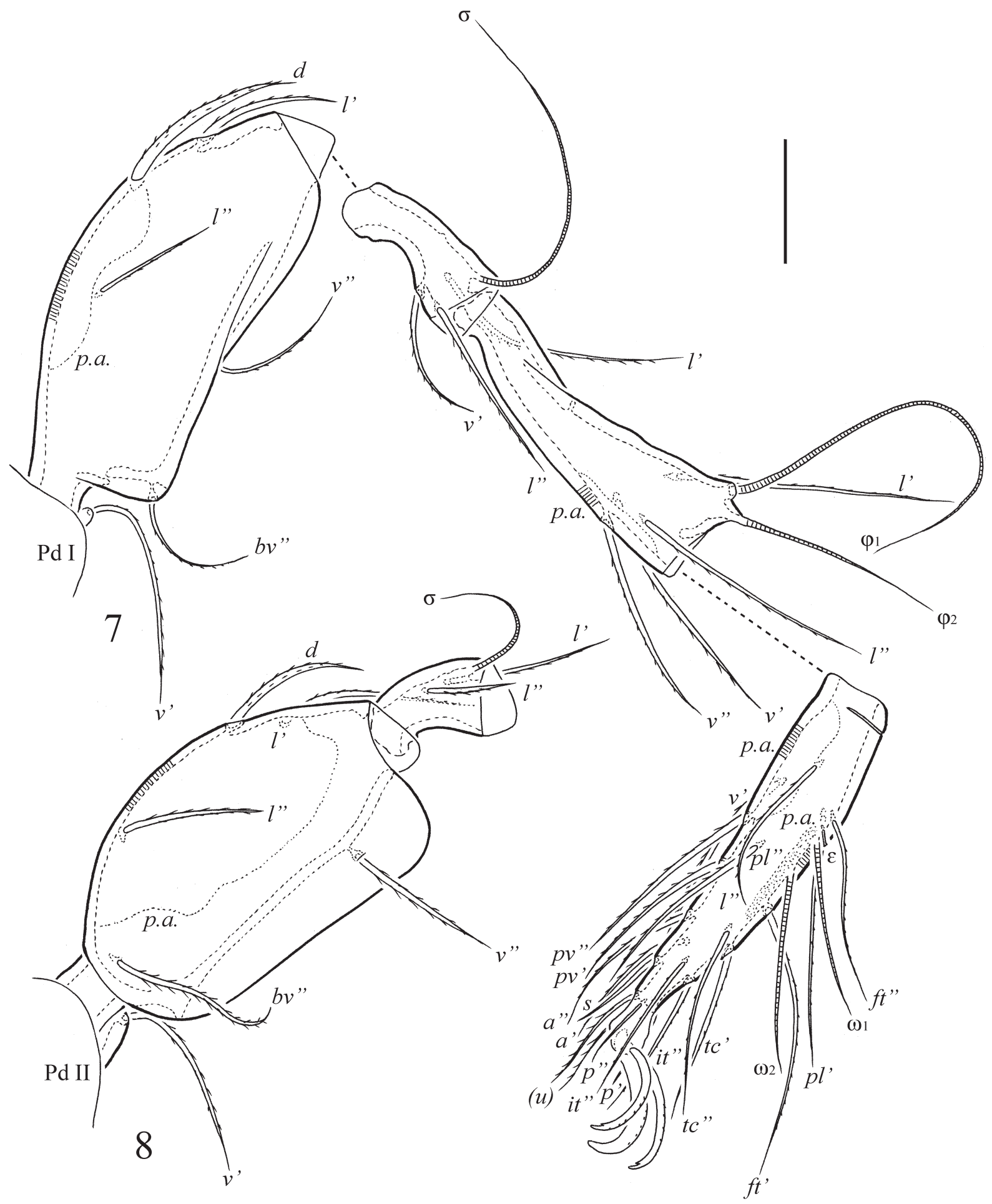

Figs. 7-8. Unguizetes clavatus Aoki, 1967: 7—leg I (trochanter covered by pedotectum I), right, antiaxial view; 8trochanter (covered by pedotectum II), femur and genu of leg II, right, antiaxial view. Scale bar $50 \mu \mathrm{m}$.

with two setiform, barbed setae, cha (73-77) longer than chb (53-57).

Epimeral and lateral podosomal regions (Figs. 2, 3). Humeral porose areas elongate oval, well separated, $A m$ diffuse, $A h$ with distinct borders. Custodia (cus) present, strong, elongate triangular. Discidia (dis) triangular, rounded distally. Circumpedal cari- nae ( $c p$ ) connected to cus. Pedotecta I (Pd I) and II (Pd II) of typical forms for the genus, Pd II with one (rarely with two) teeth lateroposteriorly in ventral view. Epimeral setae setiform, barbed, $1 b, 3 b$ and $3 c$ (61-69) longer than $1 c, 4 a, 4 b$ and $4 c$ (53-61), setae $1 a, 2 a$ and $3 a(32-41)$ shortest. 


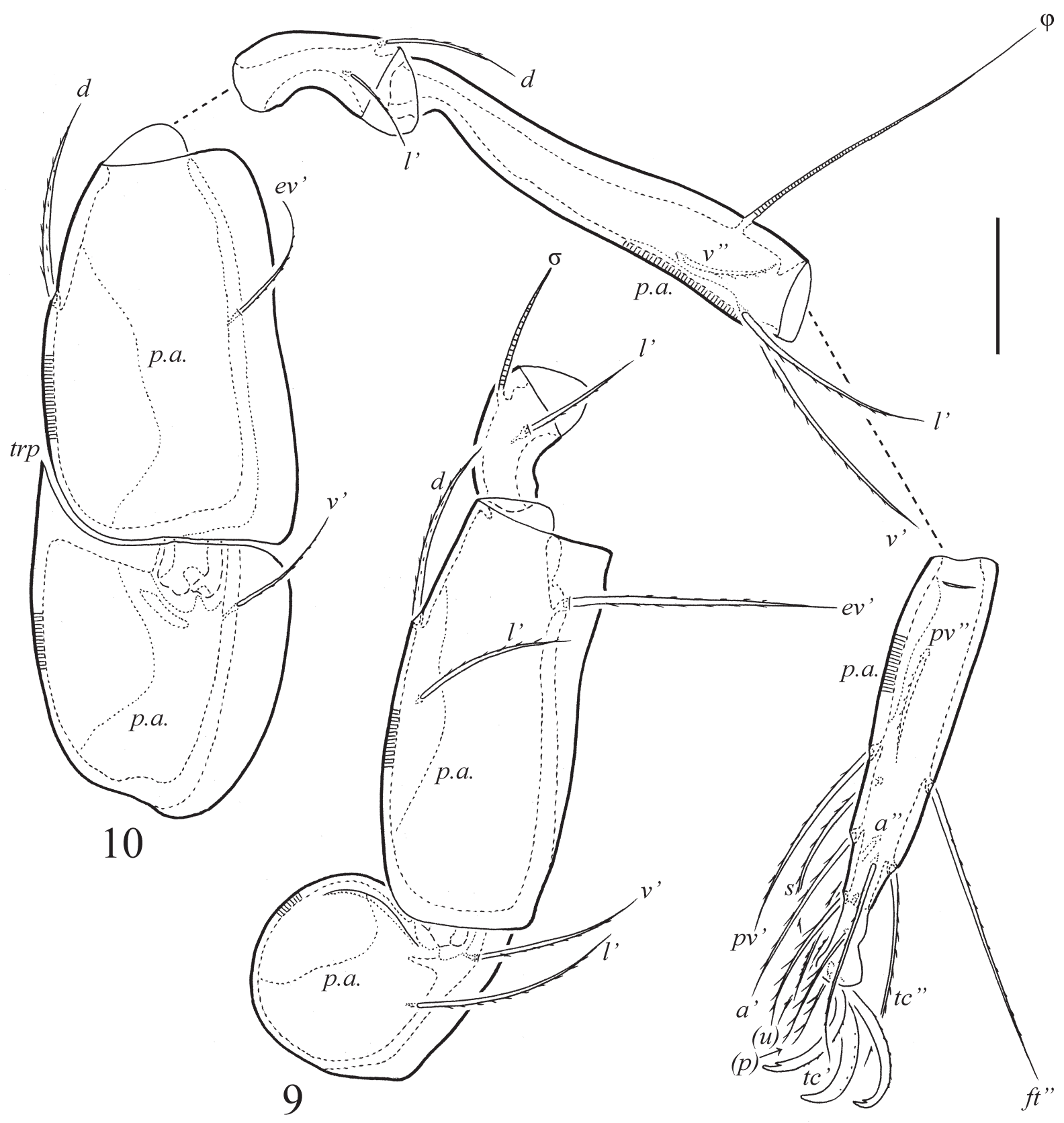

Figs. 9-10. Unguizetes clavatus Aoki, 1967: 9- trochanter, femur and genu of leg III, left, antiaxial view; 10 - leg IV, left, antiaxial view. Scale bar $50 \mu \mathrm{m}$.

Anogenital region (Figs. 2, 4, 5, 15). Six pairs of genital (32-36), one pair of aggenital (ag, 3236), two pairs of anal $\left(a n_{1}, a n_{2}, 16-20\right)$ and three pairs of adanal $\left(a d_{1}-a d_{3}, 16-20\right)$ setae setiform, thin, smooth. Adanal lyrifissures (iad) paraanal or slightly inverse apoanal. Setae $a d_{1}$ in postanal position, $a d_{2}$ in posterolateral position, $a d_{3}$ inserted anterior to iad. Marginoventral porose area (Amar) represented by numerous rounded, oval or bandlike parts.

Legs (Figs. 7-10, 24). Median claw thicker than laterals, all serrate on dorsal side, lateral claws each with small tooth ventrodistally. Trochanters III with one anteroantiaxial ridge. Trochanters IV with anterodorsal process (trp). Dorsoparaxial porose areas (p.a.) on femora and trochanters III, IV, and posteroventral porose areas on tarsi and anteroventral porose areas on tibiae well visible. In addition, dorsal porose areas present on tarsi I and II. Formulas of leg setation and solenidia: I (1-5-3-4-20) [1-2-2], II (1-5-2-4-15) [1-1-2], III (2-3-1-315) [1-1-0], IV (1-2-2-3-12) [0-1-0]; homology of setae and solenidia indicated in Table 1. Solenidia simple. Famuli $(\varepsilon)$ short, straight, slightly dilated and truncated distally, inserted posterolateral to solenidia $\omega_{2}$. 

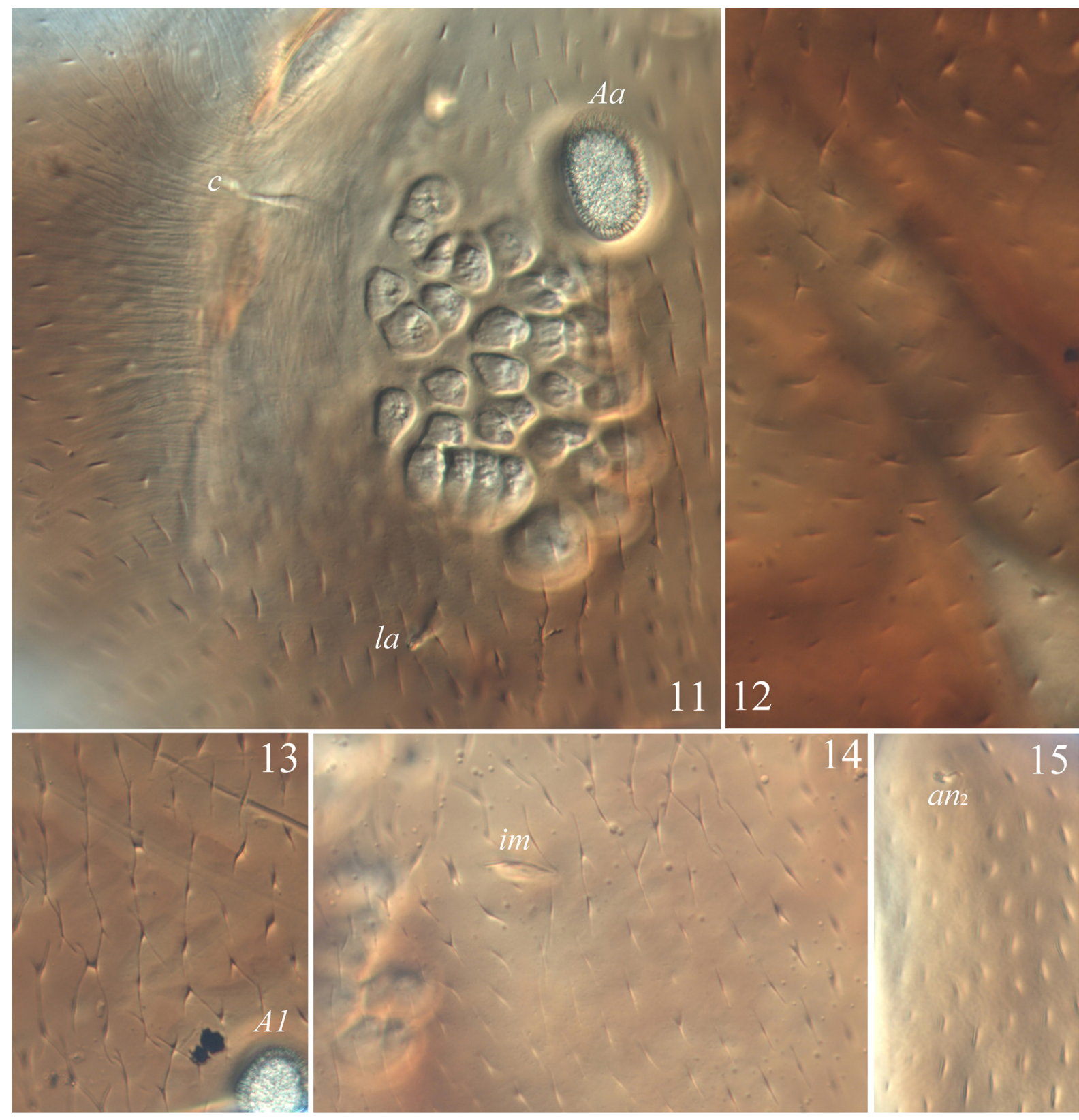

Figs. 11-15. Unguizetes clavatus Aoki, 1967, microscope images, lineolate ornamentation in dissected specimens: 11 - on notogaster near pteromorph and porose area $\mathrm{Aa} ; 12$ - in anterior part of notogaster; 13 - on notogaster near porose area $A 1 ; 14$ - on notogaster near lyrifissure $\mathrm{im} ; 15$ - on left anal plate.

Remarks. 1. Based on the supplementary description of $U$. clavatus from Northern Vietnam, known literature data (Aoki 1967) and personal data based on specimens from Southern Vietnam, I propose the following diagnostic morphological traits for this species: with main traits of Unguizetes (Ermilov 2016a); body size 680-879×498-683; surface of notogaster, pteromorphs and anogenital region lineolate/foveolate, these depressed lines or foveolae heavily or hardly developed, sometimes connected and forming striate ornamentation or reticulate pattern; rostrum rounded; lamellae with well-developed cusps having one lateral tooth; translamella thick, triangularly convex medially, with two thin, posterior ridges; prolamellae present; tutoria long, without distal teeth; rostral, lamellar and interlamellar setae long, setiform, barbed; exobothridial setae of medium size, thin, barbed; bothridial setae short, clavate, barbed; pteromorphs well-developed; four pairs of porose areas oval/ rounded. Subcapitular setae setiform, barbed, $h$ longest, $a$ shortest; humeral porose areas separated; custodia present; epimeral setae setiform, barbed; anogenital setae thin, smooth, genital and aggenital setae longer than anal and adanal setae; marginoventral porose area represented by numerous parts; 


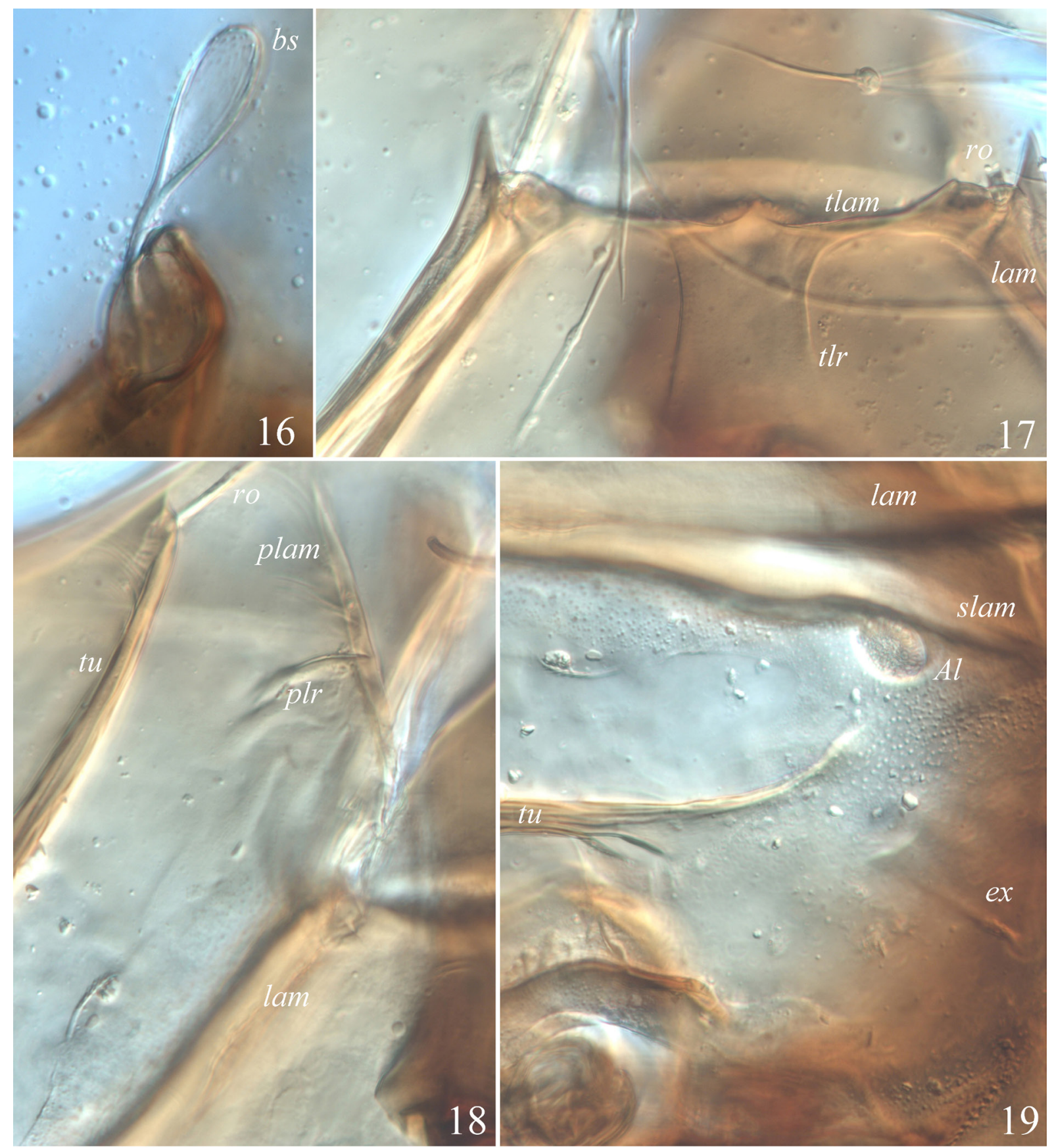

Figs. 16-19. Unguizetes clavatus Aoki, 1967, microscope images, dissected specimens: 16-bothridial seta, lateral view; 17 — translamella and anterior parts of lamellae, dorsal view; 18 — part of dorsolateral side of prodorsum; 19 — part of lateral side of prodorsum.

leg claws serrate on dorsal side, lateral claws with small tooth ventrodistally; trochanters IV with anterodorsal process; tarsi I and II with dorsal porose areas.

2. The specimens of $U$. clavatus from Northern Vietnam (data in this paper) are similar in general appearance to those from Thailand according to the original description (Aoki 1967). However, some differences are presented:

1) body surface heavily lineolate/foveolate in specimens from Northern Vietnam (vs. hardly lineolate/foveolate, poorly visible in original description, Aoki 1967);

2) setal alveoli $l m$ inserted medially or posteromedially in specimens from northern Vietnam ( $v s$. posteriorly in original description, Aoki 1967);

3 ) custodia well-developed in specimens from northern Vietnam (vs. custodia absent (?) in original description, Aoki 1967).

The specimens of $U$. clavatus from Northern Vietnam (data in this paper) are similar in general appearance to those from Southern Vietnam (per- 

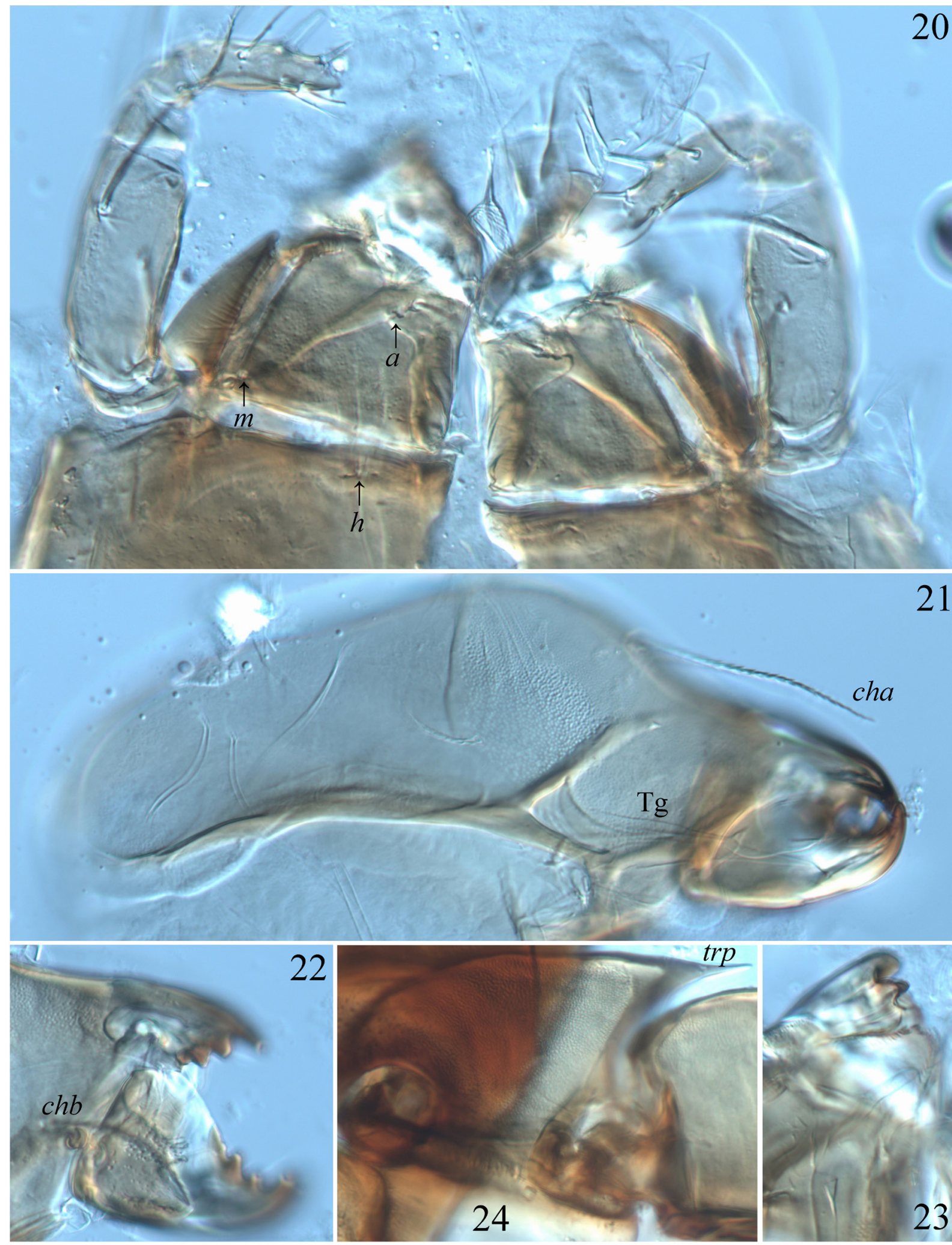

Figs. 20-24. Unguizetes clavatus Aoki, 1967, microscope images, dissected specimens: 20-subcapitulum (except basal part of mentum) and palps, ventral view; 21 - chelicera, left, paraxial view; 22 - anterior part of chelicera, right, antiaxial view; 23 - subcapitular rutellum, right, ventral view; 24 - anterodorsal process on leg trochanter IV.

sonal data; materials from Ermilov and Anichkin 2013a, b, 2014). However, some differences are presented:
1) body surface heavily lineolate/foveolate in specimens from Northern Vietnam (vs. hardly lineolate, poorly visible in specimens from Southern Vietnam); 
2) body size larger in specimens from Northern Vietnam: $813-879 \times 614-683$ (vs. body size smaller in specimens from Southern Vietnam: 680780×498-547);

3) posterior ridges of translamella well separated in specimens from northern Vietnam ( $v s$. located close to each other in specimens from Southern Vietnam).

I believe these differences represent intraspecific variability. Hence, all listed additions to the original description (Aoki 1967) and supplementary description of $U$. clavatus should be considered in any future identification of this species.

\section{ACKNOWLEDGEMENTS}

I cordially thank Dr. Josef Starý (Biology Centre v.v.i., Academy of Sciences of the Czech Republic, Institute of Soil Biology, České Budějovice, Czech Republic) for sending me Unguizetes clavatus Aoki, 1967 from Vietnam. The project was supported by the Russian Science Foundation (project 14-14-01134) and the Academy of Sciences of the Czech Republic, under Research Plan No. AV0Z606960521.

\section{REFERENCES}

Aoki, J. 1967. Oribatiden (Acarina) Thailands. II. Nature and Life in Southeast Asia, 5: 189-207.

Ermilov, S.G. 2015. A list of oribatid mites (Acari, Oribatida) of Vietnam. ZooKeys, 546: 61-85.

Ermilov, S.G. 2016a. Contribution to the knowledge of the oribatid mite genus Unguizetes (Acari, Oribatida, Mochlozetidae). Systematic and Applied Acarology, 21 (10): 1281-1299.

Ermilov, S.G. 2016b. New faunistic and taxonomic data on oribatid mites (Acari: Oribatida) of Vietnam. Biologia, 71 (4): 421-430.

Ermilov, S.G. 2017. A new species of Lohmannia (Lohmannia) (Acari, Oribatida, Lohmanniidae) from Vietnam, with supplementary description of L. (Lohmannia) turcmenica (Bulanova-Zachvatkina, 1960). Systematic and Applied Acarology, 22 (2): 193-207.

Ermilov, S.G. and Anichkin, A.E. 2013a. Checklist of oribatid mites (Acari: Oribatida) from two forest plantations of Southern Vietnam, including new records and description of a new species of the genus Suctobelbata (Suctobelbidae). Systematic and Applied Acarology, 18 (3): 225-232.
Ermilov, S.G. and Anichkin, A.E. 2013b. Collection of oribatid mites (Acari: Oribatida) from Dong Nai Biosphere Reserve of Southern Vietnam, with description of three new species. Annales Zoologici, 63 (2): 177-193.

Ermilov, S.G. and Anichkin, A.E. 2014. Two new species of Pedrocortesella, with the checklist of oribatid mites from riverine substrata in southern Vietnam (Acari, Oribatida, Pedrocortesellidae). Spixiana, 37 (2): 207-218.

Ermilov, S.G. and Starý, J. 2017a. A new species of Scheloribates (Acari, Oribatida, Scheloribatidae) from Vietnam, with key to the striolatus-group. Ecologica Montenegrina, 10: 14-21.

Ermilov, S.G. and Starý, J. 2017b. First record of the family Liacaridae (Acari, Oribatida) from Vietnam, with description of two new species. Systematic and Applied Acarology, 22 (4): 456-466.

Golosova, L.D. 1983. Some notes about oribatid mites of Vietnam. In: Golosova, L.D. (Ed.). Ecology and fauna of animals. Tyumen State University, Tyumen, pp. 41-51. [In Russian]

Minor, M.A. and Ermilov, S.G. 2015. Effects of topography on soil and litter mites (Acari: Oribatida, Mesostigmata) in a tropical monsoon forest in Southern Vietnam. Experimental and Applied Acarology, 67 (3): 357-372.

Minor, M., Ermilov, S.G. and Anichkin, A.E. 2017. Biodiversity of soil oribatid mites (Acari: Oribatida) in a tropical highland plateaux, Bi Doup-Nui Ba National Park, Southern Vietnam. Tropical Ecology, 58 (1): 45-55.

Norton, R.A. 1977. A review of F. Grandjean's system of leg chaetotaxy in the Oribatei (Acari) and its application to the family Damaeidae. In: Dindal, D.L. (Ed.). Biology of oribatid mites. SUNY College of Environmental Science and Forestry, Syracuse, pp. 33-61.

Norton, R.A. and Behan-Pelletier, V.M. 2009. Oribatida. Chapter 15. In: Krantz, G.W. and Walter, D.E. (Eds.). A Manual of Acarology (TX). Lubbock, Texas Tech University Press, pp. 430-564.

Subías, L.S. 2004. Listado sistemático, sinonímico y biogeográfico de los ácaros oribátidos (Acariformes: Oribatida) del mundo (excepto fósiles). Graellsia, 60 (número extraordinario): 3-305. Online version accessed in February 2017, 598 pp.; http://escalera. bio.ucm.es/usuarios/bba/cont/docs/RO_1.pdf

Travé, J. and Vachon, M. 1975. François Grandjean. 1882-1975 (Notice biographique and bibliographique). Acarologia, 17 (1): 1-19. 
Table 1

Leg setation and solenidia of Unguizetes clavatus Aoki, 1967

\begin{tabular}{|l|l|l|l|l|l|}
\hline Leg & $\operatorname{Tr}$ & $\mathrm{Fe}$ & $\mathrm{Ge}$ & $\mathrm{Ti}$ & $\mathrm{Ta}$ \\
\hline $\mathrm{I}$ & $v^{\prime}$ & $d,(l), b v^{\prime}, v^{\prime \prime}$ & $(l), v^{\prime}, \sigma$ & $(l),(v), \varphi_{1}, \varphi_{2}$ & $(f t),(t c),(i t),(p),(u),(a), s,(p v), v^{\prime},(p l), l^{\prime \prime}, \varepsilon, \omega_{1}, \omega_{2}$ \\
\hline II & $v^{\prime}$ & $d,(l), b v^{\prime}, v^{\prime \prime}$ & $(l), \sigma$ & $(l),(v), \varphi$ & $(f t),(t c),(i t),(p),(u),(a), s,(p v), \omega_{1}, \omega_{2}$ \\
\hline III & $l^{\prime}, v^{\prime}$ & $d, l^{\prime}, e v^{\prime}$ & $l^{\prime}, \sigma$ & $l^{\prime},(v), \varphi$ & $(f t),(t c),(i t),(p),(u),(a), s,(p v)$ \\
\hline IV & $v^{\prime}$ & $d, e v^{\prime}$ & $d, l^{\prime}$ & $l^{\prime},(v), \varphi$ & $f t^{\prime},(t c),(p),(u),(a), s,(p v)$ \\
\hline
\end{tabular}

Note: Roman letters refer to normal setae, Greek letters refer to solenidia (except $\varepsilon$-famulus). Single prime (') marks setae on the anterior and double prime (") setae on the posterior side of a given leg segment. Parentheses refer to a pair of setae. $\mathrm{Tr}$ - trochanter, $\mathrm{Fe}-$ femur, $\mathrm{Ge}-\mathrm{genu}$, Ti-Tibia, $\mathrm{Ta}$ - tarsus. 